\title{
EFFECT OF PERCEPTION DIFFERENCES IN MONEY COMMUNICATION BETWEEN PARENT-ADOLESCENTS ON FINANCIAL AUTONOMY: AN EXPERIMENTAL STUDY USING FINANCIAL EDUCATION WORKSHOPS
}

\section{JARIWALA HARSHA VIJAYKUMAR ${ }^{*}$}

1. IES's Management College and Research Centre, Bandra, Mumbai, India

* Corresponding Author: Jariwala Harsha V., Finance Department, IES's Management College and Research Centre, Bandra, 'Vishwakarma', 791 S. K. Marg, Bandra Reclamation, Bandra, Mumbai - 400050, India F +91 (22) $50001772 \quad \square$ callharsha@gmail.com

\begin{abstract}
This study evaluates the effect of parent-child money communication on financial autonomy of the adolescents by considering the gender of the parent as a controlled variable by utilizing pre- and post-survey based experimental research design. The sample consisted of 300 female parents and their children under the adolescence stage of life. Assuming parents often make that claim regarding their frequent money communication with their children, their children were asked to rate their perception towards parent's money communication with them. Later, their female parent (mother) was invited for financial education workshops series and asked to complete pre-survey before they attended the first financial education workshop. The follow-up survey was done for female parents and their adolescent children six months after completion of the financial education workshop series. In both the surveys, 300 responses were collected from female parents and adolescents on nineteen pairs of money communication, wherein parents were not told that their children were also asked to rate the matching pair of each item of parent money communication scale and vice versa. The financial autonomy was measured by using pre- and post- surveys, wherein only adolescents participated in the surveys. The results of paired t-test provide a noticeable conclusion that financial education given to the parent positively enhances money communication among parent-adolescent by reducing the disparity in the responses collected from the parents and adolescents on each matched pairs separately and collectively and this reduced disparity leads to enhance the financial autonomy of the adolescents. The findings may help policymakers and financial educators to design and implement such workshops which may open lines of "money communication" between parents and children.
\end{abstract}

Keywords: financial education workshops, parent-adolescent money communication, financial autonomy.

\section{Introduction}

The joint family system which developed in India for centuries did not leave much scope for interaction in money matters amongst the family members. Typically, in a joint family, many family members lived together with the senior-most male in the family as the head of the family known as 'Karta'. The 'Karta' was bestowed with the power to make the final decision on behalf of the family in every matter, including managing the household finances of the family. However, in the search of employment, continuous migration of the family members towards urban areas is increased, due to this traditional joint family system disintegrated and was replaced by the system of a nuclear family, wherein the adult male member of the family usually takes care of his family finances and future financial securities. This change in the family paradigm has meant that children now also need to 
be involved while taking important financial decisions. Moreover, the rapidly changing economic climate makes management of personal finances more challenging than ever before, especially for the adolescents who are about to enter the financial markets in the next decade. With the growing significance of personal money management, financial literacy becomes a key skill set in ensuring the development of a society where there is optimum utilization of the financial resources leading to greater economic development of the nation.

In India, policymakers, N.G.O.s, financial planners and educators are grappling with a situation where they need to upgrade the financial literacy level of their citizens, particularly young college students. With the improvement in lifestyle in general, the avenues for spending money have increased manifold without a corresponding similar rate of increase in income generation avenues. Since adolescents get easily attracted and are more prone to waste their money on unimportant expenses and with the plethora of personal loans and credit cards available luring the people to spend their money, there is a danger that with their limited knowledge about savings, investment and credit, adolescents may not be able to manage their finances properly which may put a strain on their own lives and in turn on the society later on.

With the traditional belief of the Indians wherein discussion about financial matters in the family is still considered as a taboo, children are still generally not encouraged to discuss the same in their families. As a result, children often have no clue about the family's financial situation. Therefore, when they grow up and start earning money themselves, they may lack the skills to manage their own money, and at some instances, they receive absurd opinions, outlooks and worries towards money (Atwood 2012).

Parents typically assume the primary role in educating their children about money management. Though, parents either lack money management skill themselves or they do not realize the significance of discussing money matters with their children. This may be due to parents' assumption that with the passage of time, their children will on their own learn these skills through observing their own habits and behaviours (Lyons et al. 2006). The literature strongly supports that the financial skills, attitudes, autonomy and behaviours can be improved through financial education (DeVaney et al. 1996; Jariwala and Sharma, 2013; Jariwala and Dziegielewski, 2017), although the parents are still considered the most influential socialization agent (Jorgensen \& Salva, 2010) and also act as a distinctive and primary source for not only gaining financial knowledge but also for developing financial autonomy for their children (Fox et al., 2000) and are considered as the essential foundation for developing positive money practices across all the generations.

Autonomy is commonly understood as a multidimensional concept that can have different scopes, such as independence, confidence (in oneself, others, and the environment), self-efficient optimism, self-control, among others. An autonomous individual takes the initiative and can recognize potentialities and weaknesses. This requires putting this knowledge into action while taking responsibility for the outcomes that result.

Existing studies on family financial communication pattern have been largely confined to spouses. Consideration of children in money communication is equally important. In every family structure directly or indirectly, money matter is discussed among family members through frequent discussions wherein parents provide the appropriate lessons and learning to their children for managing their personal finances. The Theory of Social Learning Opportunities strongly supports that the parentchildren interactions on personal finances are the crucial attributes to develop positive financial practices and financial autonomy (Kalil et al., 2005). This supports the presence of an association between parent, child and financial education, which is yet not explored by the researchers.

In India, under the present financial education efforts of the government authorities, financial literacy efforts are manifested through financial education workshops under the aegis of regulatory authorities such as Securities and Exchange Board of India, Reserve Bank of India, Insurance Regulatory and Development Authority of India and Ministry of Corporate Affairs. The financial 
education material is designed and developed and is used at financial education workshops conducted for specific target groups such as school students, college students, middle-income groups, retirees and homemakers etc. Further, all the regulatory authorities have joined hands to promote financial literacy on a common platform by establishing a National Centre for Financial Education which takes care of promoting financial literacy among school children through various strategies. However, there are not many research studies available onthe effectiveness of financial education program evaluation. This point is emphasized by Lusardi (2011) who observed that there is scope to assess impact evaluation of such programs studying other behavioural outcomes.

The instant study is an attempt to bridge the above gap. It is an outcome-based experimental study that has attempted to answer several research questions and contributing to behavioural finance that has implications for managerial decisions at the macro level. The study attempts to address firstly whether the financial autonomy of the adolescents is affected by the parent-child money communication and secondly, whether the parent-child money communication can be enhanced if the financial education is given to the parents? Lastly, if the parent-child money communication is enhanced by financial education, then does this reduced gap of money communication among them leads to enhance the financial autonomy of the adolescents.

This paper follows a definite structure that discusses the literature review based on financial education program evaluation, theoretical support, research method and procedure, and discussion of the results of this empirical study. The paper concludes with a discussion on suggestions to various stakeholders based on the inferences derived and provides direction for future research in this area.

\section{Literature Review}

Literature in sociology and psychology explainsthat autonomy includes the attributes of independence, confidence, optimism, self-control, and conformity to parents and peers (Steinberg \& Silverberg, 1986). Noom et al. (2001) blended three forms of autonomy, attitudinal/reflexive, emotional, and functional. Attitudinal/reflexive autonomy was described as the ability to set goals and think before acting and encompasses the notions of knowledge, consciousness, and responsibility. Emotional autonomy brings confidence in one's own choices, whether being expressed to parents, relatives, or peer groups. Lastly, functional autonomy encompasses a regulatory dimension where different approaches may be selected to achieve the goal. With each approach, selected competence, control and responsibility is displayed. One important aspect of autonomy is self-motivation. When people feel empowered, they are generally got motivated to attempt the change-making strategy. Several theorists believe in the importance of motivation and selfdetermination (Ryan \& Lynch, 1989; Connell, 1990;), and self-efficacy (Bandura 1989; 1997). Autonomy is evident in intrinsic motivation to engage in certain behaviours and joy in choosing to engage in certain behaviours rather than others. Different strategies to achieve goals are attempted, and choice of a specific strategy is founded on knowledge-based decision-making, that has been derived from the attributes at a personal level, family relations and the parent-children interactions (Kalil et al., 2005) and the distinctive and primary source for gaining financial knowledge for the children (Fox et al., 2000) and are considered as the essential foundation for developing financial autonomy across all the generations.

The literature argues that the autonomy is an "integrative model" (Noom, et al. 2001), where measuring fluctuating domains of financial autonomy is equally important as the autonomy is basically developed in the stage of adolescence and throughout the lifecycle span, the autonomy improves and falloffs as individuals develop new competencies, previously acquired skills may also decline, and changing conditions will continue to require altered behaviour (Baltes\& Silverberg 1994). Throughout adulthood, autonomy continues to develop especially when someone is 
confronted to act with a new level of self-reliance that requires the specific skills to display the best outcomes. Literature documented that one of the significant attributing factors in the parental [financial] socialization education is involvement in direct and open discussions regarding buying judgments, cash, credit, and topics related to money (Allen, 2008).

In recent times, money communication with children has become a complex issue with a plethora of complex information overload and a variety of financial markets and products. Furnham and Argyle (1998) pointed out that there is no agreement about how to teach children about money; however, there is a common opinion that money management should be taught to children and it is the parents who should initiate their children into money education. Mandell (2001) explained that children's financial knowledge and skills could be enhanced by the financial management discussions between parents and children. Violato et al. (2011) explained that through money communication, parents may explicitly transfer financial knowledge and skills to their children and the children can then further that knowledge and skill to be able to deploy more complex and sophisticated financial strategies. (Otto, Schots, Westerman, \& Webley, 2006). Koonce et al. (2008) also observed that teens who exhibited mature financial behaviour and set financial goals and were savers are the ones with whom their parents regularly discussed finance and investment. Webley \&Nyhus (2006) acknowledged money communication by explaining that adults who had greater interaction with their parents about money matters during childhood had more propensities to save and not spend their excess income. Thus, parent-child money communication means that children are more confident in making financial choices.

Previous studies also confirm that the emotional atmosphere in the family also plays an important role to develop financial autonomy among adolescents. It is always observed that the parents often interact, communicate, monitor set the rules, provide the guidance, and monitor the same regarding financial attitudes and practices to nurture future adaptive financial practices in their children. Many studies confirm that the existence of the emotional climate in the family is equally important in encouraging adaptive monetary practices. Laible\& Thompson (2007) argue that for children, the warm parent-child interactions nurture inspiration to accomplish and cooperate with parents. In a supportive emotional climate, children always feel free to discuss money matters with the parents, and this ultimately results in the enhancement of financial autonomy.

Financial Literacy \& Education Commission (2006) had pointed out the lack of personal financial knowledge as a major barrier to an individual's sound financial practices. "The ...absence of this knowledge and skill poses a variety of risks to individuals, society and economy as a whole" (Sharma \& Jariwala 2011).In current times, financial skills are essential prerequisite to manage personal finances. Complex financial products and services, attached to financial engineered innovations, continuous transfer of financial risk from the government to households have put massive responsibilities and stress on individuals for securing and maintaining their economic well-being. Kim (2001) explained the significance of financial knowledge to enhance the financial well-being of the people. Financial education plays a pivotal role in helping people to acquire the requisite skills and exercising optimum choices and taking appropriate informed and autonomous financial decisions. (Joo, 2008).

Prior studies suggest that financial education not only improves financial literacy but also leads to an improvement in the way people deal with financial matters. Hogarth et al. (2003) observed that financial education leads to better financial choices being made by people in their personal financial matters. Mandell (2009) stressed that though financial literacy develops positive financial behaviour, its effect on long-term financial behaviour is still not certain. Lyons et al. (2006) studied how financial education changed people's behaviour and concluded that education has the greatest effects on short-term financial behaviours. Lusardi (2004) confirmed that after attending retirement seminars, not only the participants' private financial wealth increased but also there was an improvement in pension and social security wealth. DeVaney et al. (1996) assessed what impact financial education had on women credit card customers and came out with the result that as a result of financial education workshops, many of these women have minimized the usage of their 
credit cards and at the same time started saving more money. Germam et al. (1999) explained that after attending financial education workshops, participants not only made "better and more informed financial decisions but also felt more confident while making investment decisions. Indian studies also confirmed that financial education not only profoundly improves the way people manage their cash flows, saving, investment and credit behaviour (Jariwala and Sharma, 2013), but also enhancement of various types of financial autonomy such as reflexive autonomy, emotional autonomy and functional autonomy (Jariwala \&Dziegilewski, 2017) among the women participants.

\subsection{Research Questions}

The above literature presented on evaluation of financial education workshops concluded that financial education leads to positive financial outcomes whereas the literature discussed the importance of parent-child money communication in the family concluded that money communication plays an essential role in developing the desired positive financial practices, financial behaviour and financial autonomy of their children during their adulthood. Considering the importance of money communication in parental financial direct teaching, this study has attempted to answer the following key research questions. Firstly, whether the financial autonomy of adolescents is affected by parent-child money communication? Secondly, whether the parent-child money communication can be enhanced if the financial education is given to the parents by considering the parental gender as a controlled variable as there is evidence that in an Indian family, parents generally find it uncomfortable to talk about money with their children? The studies in this regard have found that parents in India are very sensitive about discussing money with their children and deem money in the same category as puberty and sex which according to them are taboo topics that should not be discussed with children. Lastly, if the parent-child money communication is enhanced by the financial education, then does this reduced gap of money communication among them leads to enhance the financial autonomy of the adolescents.

\subsection{Theoretical framework}

The Communication Privacy Management Theory (Petronio, 2002), Social learning theory (Bandura, 1986) and the Transtheoretical model of behavioural Change (Prochanka,1979) provide theoretical support to this study.

The Communication Privacy Management Theory proposes three assumptions. Firstly, individuals are unsure about whether to share personal information or not. Secondly, individuals make their boundaries to control the movement of their private information wherein; these boundaries help an individual to establish whom the information will be shared with, as well as to what extent information sharing will occur assuming that as soon as private information is shared with someone else, this person then becomes co-owner of the information and is included within the boundary set, irrespective of the person's characteristics or how receptive the individual is. The third hypothesis proposes that people construct own rules on how open or close these boundaries will be and how much they will reveal or conceal of their personal information wherein these mental boundaries are set by considering risk-benefit principle. If an individual perceives that more benefits will accrue than the risk of revealing personal information, then they would prefer to reveal such information. On the contrary, if they feel that the risk is more than the benefit, then they will feel apprehensive and therefore, prefer to conceal the information (Petronio, 2002). Applying this to parent-child money communication, the huge divergence found from the responses collected on money communication perception from parents and adolescent children in the pre-survey data confirmed that parents either have limited or no conversation with their children on the subject of money (supported by the first hypothesis). This may be due to a child may not be mature enough to understand the sensitive matters related to money (supported by the second hypothesis). Lastly, if a parent fears being judged by their child on the money matter, they would rather conceal the information. Individuals, who are ashamed, feel guilty or attach their self-esteem to their financial situation, would perceive the risk of revealing personal financial information as too risky and would therefore be reluctant to disclose information (supported by the third hypothesis). 
Social Learning Theory (Bandura, 1986) also provides theoretical support to this study, and it suggests that parent's communication about financial topics with their children is essential. It explains that children are explicitly and cognitively influenced by their parents through direct education, instruction, reinforcement and purposive modelling held with them. Further, the socialization process originates in childhood, and it progresses during the entire lifespan. Financial socialization is learned in such a waythat individuals acquire knowledge about money, money management and enhance their abilities and expertise in numerous financial practices through direct instructions from the parent or their observation. Danes (1994) proposes that the family is always considered as a key and primary source of children's socialization; wherein children observe their parents, participate in financial practices, and receive direct objective instruction from parents.

Lastly, the Transtheoretical Model of Behavior Change (Prochanka, 1979) underpins the different levels of readiness to change problem behaviour or develop a desirable new behaviour, that includes six steps which are (a) pre-contemplation, (b) contemplation, (c) preparation, (d) action, (e) maintenance, and (f) termination. The movement to a higher level of readiness to change behaviour is influenced by the processes of change which include activities and experiences that individuals engage in as they attempt to modify their behaviour. The purpose of this study was to assess the behavioural change in money communication among the parent-adolescent after providing financial education to the parents, controlling the parent's gender. In this study, the money communication perception divergence was higher among parent-adolescent, and later this was drastically reduced signifying that parents have developed behaviour that supports the money communication with their children that was depicted in the follow-up survey of this study. This continuous level of change behaviour is depicted in the Transtheoretical Model of Behavior Change, as suggested by Prochanka (1979).

\section{Research Methodology and Procedure}

This study was conducted in the Gujarat State of India. According to the population census of India (Government of India, 2011), the literacy rate in Gujarat shows an upward trend and is 79.31 per cent. Out of this, the male literacy rate stands at 87.23 per cent, whereas female literacy rate is at 70.73 per cent. The geography of this state is divided into twenty- two districts. Out of these, the district of Mehsana was selected at the convenience of the researcher. In this region, there are total thirty-nine Grant-in-Aided secondary schools registered under Gujarat State Secondary Education Board, wherein the medium of instruction is Gujarati (i.e. the regional language of the state of Gujarat). The researcher has randomly approached the Principal of total six schools at the beginning of the academic year 2018-19, i.e. the month of July 2018, out of this, three school Principals granted their permission to conduct financial education workshops and further to collect the pre-workshop and post-workshop follow-up data collection in the school premises.

The literature on family socialization reports that gender plays an important role in socialization. Hence, in this study, the gender of the parent was controlled to assess the effect of financial education on money communication among parent-adolescent.

The financial education workshops were targeted at female parent because of following reasons. Firstly, the school record of previous three parent-teacher meetings was studied in the selected schools, and it was found that these meetings were attended mostly by the female parent. The records also showed that many of the male parents were employed in the private sectors wherein taking leave from their workplace to attend the meetings were difficult for them. It was assumed that if male parents were also invited to attend a financial education workshop series at school, then it was difficult for them to take leave from their workplace to attend such a workshop series. Secondly, the women from this region were mainly homemakers who are engaged in daily household duties. 
Due to the male-dominated social structure, the male takes care of all personal finances. Sometimes, it is observed that due to the male-dominated social structure, women voluntarily exclude themselves from actively participating in household money management. Thirdly, there is evidence that women are less financially literate (Lusardi and Mitchell, 2009), less confident (Taylor, 2003) and less knowledgeable (Chen and Volpe, 1998) than men in the subject of personal finance and compared to men; women are more conservative in investment practices (Bajtelsmit and Bernasek, 1996). Thus, females are in urgent need of financial education. This study assumes that if financial education is given to women (parent), then this will not only enhance their confidence while dealing with financial matters but also help them to build their wealth and proper asset allocation of their family.

Accordingly, the overall objective of the financial education workshop series was to make female parent aware of the topic of personal finance and enhance their capability to identify financial opportunities and likely consequences. However, the primary objective of this study was to assess the impact evaluation of the financial education workshop series on parent-adolescent money communication by controlling parents' gender.

The population of the study was a female parent and adolescent children since in this stage; children start to develop their autonomy, wherein autonomy refers to an adolescent's growing ability to think, feel, make decisions, and act on his/her own. Autonomy concerns the experience of integration and freedom (Desi \& Ryan, 2000) and the development of financial autonomy also takes place which refers to individual's ability to decide freely on his/her financial affairs. The ability to manage the funds independently enables him/her to set and realize his financial goals. This ranges from freedom from the constraints of (financial) dependence on others to freedom to make (financial) choices, pursue (financial) goals, and so forth (Collins, Gleason, \&Sesma, 1997) and resulting into financial autonomy.

For the selection of the participants, the Principal of respective schools understudy was requested to allocate two classes in which adolescent children pursue their study. In the Indian context, this age of adolescence is considered as of 10 to 19 years (Population Census, Government of India, 2011). Accordingly, the classes of having students in the age group of 13 years to 15 years were selected. The students of this age group were found in Standard VII, VIII, IX. Each standard consists of three sections namely Section A, Section B, and Section C. Out of these, two sections were selected randomly to reduce the effect of potential biases that may happen due to self-selection of the respondents under study. Total 120 students from two sections of Standard VII from "School 1", 110 students from two sections of Standard VIII from "School 2" and 105 students from two sections of "School 3" were approached during their regular classes. On the suggestion of two School Principals, the students in the extreme lowest age and highest age of adolescence were not considered since at the respective life stages, children are either too immature or might have already developed some sense of autonomy.

The total number of students from the schools mentioned above was 335 adolescents. Firstly, these students were approached in August, 2018, i.e. after completion of one of the academic years and a questionnaire that consisted of nineteen matching paired items of money interaction scale prepared for children on the five-point likert scale ranging from 1=Always, 2=Sometimes, 3=Neutral, $4=$ Almost never and $5=$ Never were circulated to them, and they were requested to rate each variable by recalling money communication held between them and their mother and fifteen items of financial autonomy.

After collecting filled up a questionnaire, these students were given information that school authority along with one of the certified trainers for financial education as certified by the national authority who also works as a resource person for promoting financial literacy is going to teach basic money management to their female parent (mother) through financial education workshop series. For this, their mothers need to come to schools on six occasions at a regular interval of twenty days to attend two to three hours during noon on working days. All the students confirmed that their mother would 
come to take advantage of this workshop series. The students were also requested not to share with either of their parents about the questionnaire that they have filled up.

The workshop series consisted of four workshops of approximately two hours, out of this five workshops covered various topics on management of personal finances such as (i) difference between want, need and demand, (ii) prioritization of financial needs (iii) spending choices (now and later) (iv) basics of budgeting, ( $\mathrm{V}$ ) planning expenditure, (vi) creating fund for unplanned expenses/ emergencies, (vii) S.M.A.R.T. goal setting, (viii) basics of saving and saving bank accounts (ix) investment options with risk and return trade off, $(x)$ interest rate and its method for calculation, (xi) rule of 72 (xii) power of compounding, (xiii) taxation aspects, (xiv) choosing right investment avenue $(x v)$ inflation and its effect on investment (xvi) need for risk cover, (xvii) types of life insurance policies and factors to be considered while getting insured, (xviii) need for health insurance policy and other aspects of the same (xix) understanding credit and its handling, credit score (xx) retirement planning (xxi) importance of careful reading of document before investing or taking credit, (xxii) identification of Ponzi schemes (xxiii) investor protection and grievances redressal mechanisms and taking consumer action. The last (i.e.), the fourth workshop consisted of the importance of family communication on the topic of household finances and its likely consequences. Each workshop was followed by question-answer sessions. The language of subject delivery was Gujarati, which is the regional language of Gujarat state. The financial education material developed by various authorities such as Securities and Exchange Board of India, Reserve Bank of India, Insurance Regulatory and Development Authority of India and educational institutes of national repute such as National Centre for Financial Education was downloaded from their respective websites and used for this workshop series. The financial education subject material developed by the Securities and Exchange Board of India for homemakers in the Gujarati language was distributed to the participants free of cost.

Looking to the efforts and monetary resources employed in designing and implementing financial education workshops, numerous researchers have suggested the standard structure to evaluate financial education programs that can serve as a guideline not only for the designers of financial education programs for its effective outcomes but also for the researchers for employing the best practices for program evaluation. O'Connell (2009) proposed a new version of a five-tier framework. He suggested that financial education workshops are to be assessed by identifying program needs, accountability, fine-tuning, micro- and macro impacts of such programs. Accordingly, it is assumed that "parent-adolescent money communication" can be enhanced (in other words impacted positively) when parents are empowered about personal finance. Thus, analysis of the program impact comes under macro-impact of program evaluation as suggested by O'Connell. Further, Lusardi (2011) explained the existence of enough scope to study the effect of a financial education program on various outcomes, as the existing literature on effects of evaluation of financial education programs is limited.

The present study utilizes before-and-after without control design under the experimental research designs, wherein a test group is selected, and the dependent variable is measured before the introduction of the treatment. The treatment is then introduced, and the dependent variable is again measured after the treatment has been introduced. The effect of treatment would be equal to the level of the phenomenon after the treatment minus level of the phenomenon before the treatment.

\subsection{The survey instrument}

The survey instrument consisted of nineteen items of money communication (interaction) scale adapted from money interaction scale (Moore \& Stephens, 1975; Moschis, 1978) and consumer activity scale (Moschis\& Churchill, 1978) and fifteen items of financial autonomy scale (Micarello, Melo, Marcelo et al., 2012). The money communication (interaction) scale consisted on matched pairs (of each money communication questions for parents) for adolescent of total nineteen items of communication about money between parent and adolescent (Refer Appendix 1). As discussed earlier, initially questionnaire consisting of matching paired questions of each variable of the scale 
was distributed to the adolescent students in the classroom before conveying that their mother would be given financial education. These students were asked to rate their perception towards their existing money communication with their female parent (i.e. mother) on the likert scale on each matched pair ranging from $1=$ Always, $2=$ Sometimes, $3=$ Neutral, $4=$ Almost never and $5=$ Never. Similarly, when their mother came to attend the first financial education workshop, before starting of the first workshop, each mother was asked to fill up the questionnaire that consisted of their demographic and socio-economic variables and nineteen items of money communication for a parent. They were asked to rate each item on likert scale ranging from 1=Always, $2=$ Sometimes, $3=$ Neutral, $4=$ Almost never and $5=$ Never.

The financial autonomy index consisted of 15-items divided into three sections: reflexive autonomy, emotional autonomy and functional autonomy were circulated among the adolescent students before it is conveyed that their mother would be invited for attending financial education workshops and were asked to rate each variable. Each of the 15 statements was calculated on a 5-point scale: "This sentence is a very bad description of $m e "=1$; "This sentence is a bad description of me" = 2; "This sentence is an average description of $m e "=3$; "This sentence is a good description of me" = 4; and "This sentence is a very good description of me" $=5$. Questions related to the autonomy measure were designed to capture the adolescent's confidence, independence, and willingness to participate and influence (household) financial decisions. For example, the survey asked the adolescents the extent to which they agree or disagree with statements on (i) reflexive/attitudinal autonomy, such as "I like to think carefully before deciding to buy something;" (ii) emotional autonomy, such as "I feel prepared to talk to my parents about money matters;" and (iii) functional autonomy, such as "I always try to save some money to do things I really like." Five questions were asked in each category, totalling 15 questions.

Assuming that parents always claim that they usually discuss money importance and its management with their children, but their children don't 'hear' them, the matched pair of each money communication item of nineteen variables framed in the structured questionnaire was also rated by children who were in adolescence stage of life on each matching item pair of the parent scale. However, parents were not told that their children were also asked to rate the matching pair of each item of parent money communication scale and vice versa. Accordingly, these adolescents rated the matching version of parent-adolescent money communication scale twice, before conducting the first financial education workshop and six months after completing the last workshop of their female parent along with the financial autonomy scale.

The workshop series was conducted fromSeptember 2018 to January 2019. The follow-up survey was conducted after six months of the completion of the last workshop at each school. For this, students were approached in the same classroom and were asked to rate the questionnaire consisting of the same items previously. Similarly, after approximately six months of the completion of the workshop series, during mid-year parent-teacher meeting, once again these female parents were approached and were requested to fill the same questionnaire and complete the follow-up survey. It was found that the financial education workshop series was started with 335 female parent participants (as total students were 335). However, 17 participants dropped out voluntarily, while 18 female parents did not attend the follow-up survey. Thus, the sample size for this study came to 300 female parents. The profile of the sample is presented in Table 1.

Money communication score was calculated by taking the absolute value of the differences between the rating given by the female parent and the child of the adolescent stage on every nineteen comparable items and then summing up those differences. E.g. the lowest possible score was zero, and the highest possible score was 76. The higher the score, the greater the disparity between the parent and adolescent regarding their perception of their money communication. Accordingly, money communication score was calculated twice, i.e. based on the analysis of the responses given by the parent and adolescent in the pre-survey and the post-survey. These 
calculated values of money communication were used to develop the research hypothesis for this study.

\section{Data Analysis and Interpretation}

Descriptive statistics, reliability analysis and paired t-test, were conducted to study the research objective.

The profile household is presented in Table 1 (A) and (B).

Table 1a: Sample Profile of Adolescent students (Children)

\begin{tabular}{llrr}
\hline Variables & Categories & Frequency & in per cent \\
\hline \multirow{3}{*}{ Age } & 13 years & 92 & 30.67 \\
& 14 years & 95 & 31.67 \\
\multirow{2}{*}{ Gender } & 15 years & 113 & 37.67 \\
\hline \multirow{2}{*}{ How much Pocket money you receive monthly y } & Male & 188 & 62.67 \\
& Female & 112 & 37.33 \\
\cline { 2 - 4 } & Below Rs. 50 & 48 & 16.00 \\
& Rs. 51 to 100 & 65 & 21.67 \\
& Rs. 101 to Rs. 150 & 104 & 34.67 \\
\multirow{2}{*}{ With whom you discuss your personal matters } & Above Rs. 150 & 83 & 27.67 \\
\hline \multirow{2}{*}{ Total } & Mother & 218 & 72.67 \\
& Father & 82 & 27.33 \\
\hline
\end{tabular}

Table 1b: Sample Profile of Female Parent

\begin{tabular}{llrr}
\hline Variables & Categories & Frequency & in per cent \\
\hline \multirow{4}{*}{ Age } & 30 to 35 years & 52 & 17.33 \\
& 35 to 35 years & 142 & 47.33 \\
& 35 to 40 years & 70 & 23.33 \\
& Above 40 years & 36 & 12.00 \\
\hline \multirow{3}{*}{ Household Monthly Income } & Below Rs. 15,000 & 42 & 14.00 \\
& Rs. 15,001 to Rs. 30,000 & 78 & 26.00 \\
& Rs.30,001 to Rs. 45,000 & 76 & 25.33 \\
& Rs. 45,001 to Rs. 60,000 & 84 & 28.00 \\
& Above Rs. 60,000 & 20 & 6.67 \\
\hline \multirow{3}{*}{ Education } & Upto Class 10 & 32 & 10.67 \\
& Upto Class 12 & 48 & 16.00 \\
\hline Total & Graduate & 158 & 52.67 \\
\hline
\end{tabular}

\subsection{Data reliability}

Cronbach's coefficient was used to check the scale reliability. The Cronbach's a was calculated at two stages: (i) Pre-survey and (i) Post-survey. The value of Cronbach's a coefficient for money communication scale for the pre-survey were 0.879 and 0.783 for the parents and adolescents. Similarly, these values arrived at 0.756 and 0.767 from the analysis of responsescollected from parents and adolescents in the post-survey. The Cronbach's a coefficient value for the financial autonomy scale were 0.844 and 0.747 in the pre-survey and post-survey, respectively. Thus, the a values for money communication scale under both the surveys indicate an acceptable level of internal 
consistency among the variables confirming that the scale is reliable enough to use. Similarly, data quality was checked by using Skewness, Kurtisis and t-test values, showing data are normal.

\subsection{Data analysis}

Data analysis is done to check the following research hypotheses that are framed based on in-depth literature review and primary research questions of this study.

1. HO : There is no significant difference between parent-adolescent money communication disparity score before and after providing financial education to the female parent.

2. $\mathrm{HO}_{2}$ : There is no significant effect of money communication (interaction) gap on the financial autonomy of the adolescents.

Paired t-test was conducted to check the study hypothesis 1. Table 2 displays the calculated mean, standard deviation, and standard error of the means of all nineteen pairs of money communication under study. The effect of financial education provided to the female parent las gender is the controlled variable) can be seen by analyzing the mean values of each variable of money communication of pre-workshop survey and post-workshop survey. The careful examination of mean values of each pair as presented showed that for all the variables mean value for the pre-workshop survey and post-workshops survey show significant differences (see Table 2).

The results of the paired t-test are presented in Table 3. The t-test values presented in the last column of Table 3 shows the significance values for the two-tailed test at the at 5 per cent level of significance. The differences in mean value reported in the third column of Table 3, shows that there is a difference between pre-survey and post-survey money communication perception among parent-adolescent is improved significantly six months after the completion of workshop series for all 19 pairs of money communication items. E.g., for Pair 1 decoded as "I talk to my child about buying things" (parent scale) and "This parent and I talk about buying things" (matching pair for adolescent scale), the mean value for the disparity in money communication perception reported by parentadolescent in the pre-survey was 1.98 (SD = 0.836) and in the post-survey was 0.97 (SD = 0.786) († (299) $=19.27, \mathrm{p}<0.05)$. This reports that financial education given to the parent has significantly improved money communication perception between parent and adolescent. Similarly for "I go for shopping with my child" (parent scale) and "I go for shopping with this parent" (adolescent scale) that is coded as pair two reported that the disparity in the mean value of money communication perception of parent-adolescent for this variable is improved to 1.20 ( $S D=0.787$ ) in the post-survey from the mean value of $2.68(S D=0.833$ ) as reported in post-survey.

The careful analysis of mean values for each pair of parent-adolescent money communication presented in Table 2 suggests that the disparity in the mean value of perception of parentadolescent for pair 16, pair 15 and pair 6 was the highest. Among these, the mean value disparity for pair 16 decoded as" I allow my child to manage their own money" (parent scale) for which is matched pair for adolescent was "This parent allows me to manage my own money", was the highest among all 19 pairs, and was found to be 2.91 (SD = 0.813) in pre-survey and 0.80 (SD =0.700) (t (299) $=32.65, \mathrm{p}<0.05)$ in the post-test, that was followed by the Pair 15 presented as "I help my child developfinancial goals" (parent scale) for which matched pair was "This parent helps me develop financial goals" (adolescent scale), for which reported disparity in the mean value was improved from 2.57 ( $S D=0.984)$ in pre-survey $0.58(S D=0.581)(\dagger(299)=29.78, p<0.05)$ in post survey; compared with Pair 6 represented as "I tell my child why I bought some things for myself" (for parent scale) for which matched pair was "This parent tells me why they bought some things for themselves" (adolescent scale), for which disparity in the mean value was 2.34 (SD $=1.175$ ) in pre-survey 0.78 (SD $=0.946)(\dagger(299)=16.78, p<0.05)$.

The analysis of all matched pairs of 19 items of parent-adolescent money communication also reported disparity in the mean value of perception of parent-adolescent for Pair 3, Pair 7 and Pair 4 was the lowest. Among these, for pair 3 decoded as "I tell my child what things he or she should or 
should not buy" (parent scale) for which is matched pair for adolescent was "This parent tells me what things I should buy or not buy", was the lowest among all 19 pairs, and was found to be 1.96 (SD = 0.635 ) in pre-survey and $0.97(S D=0.628)(t(299)=111.98, p<0.05)$ in the post-test, that was followed by the pair 7 presented as "I talk to my child about saving and investing money" (parent scale) for which matched pair was "This parent and I talk about saving and investing money." (Adolescent scale), for which reported disparity in the mean value was improved from 1.71 (SD $=0.999$ ) in presurvey 0.71 (SD $=0.663)(\dagger(299)=21.47, p<0.05)$ in post survey; compared with pair 4 represented as "I tell my child what to do with his or her money" (for parent scale) for which matched pair was "This parent tells me what they do with their money" (adolescent scale), for which disparity in the mean value was $1.98(\mathrm{SD}=0.936)$ in pre-survey $0.96(\mathrm{SD}=0.919)(\dagger(299)=14.07, \mathrm{p}<0.05)$.

Table 2: Paired Samples Statistic

\begin{tabular}{|c|c|c|c|c|c|c|c|}
\hline Pairs & Money communication scale for parents & Codes & Mean & $\mathbf{N}$ & $\begin{array}{l}\text { Std. } \\
\text { Deviation }\end{array}$ & $\begin{array}{l}\text { Std. } \\
\text { Error } \\
\text { Mean }\end{array}$ & $\begin{array}{r}\text { Cohen's } \\
\text { d }\end{array}$ \\
\hline \multirow{2}{*}{ Pair 1} & \multirow{2}{*}{$\begin{array}{l}\text { I talk to my child about buying things. } \\
\text { (MCl) }\end{array}$} & MCEl & 1.98 & 300 & 0.836 & 0.048 & 1.294 \\
\hline & & MCP1 & 0.93 & 300 & 0.786 & 0.045 & \\
\hline \multirow{2}{*}{ Pair 2} & \multirow{2}{*}{ I go shopping with my child. (MC2) } & MCE2 & 2.68 & 300 & 0.833 & 0.048 & 1.815 \\
\hline & & MCP2 & 1.2 & 300 & 0.787 & 0.045 & \\
\hline \multirow{2}{*}{ Pair 3} & \multirow{2}{*}{$\begin{array}{l}\text { I tell my child what things he or she } \\
\text { should or should not buy. (MC3) }\end{array}$} & MCE3 & 1.96 & 300 & 0.635 & 0.037 & 1.558 \\
\hline & & MCP3 & 0.97 & 300 & 0.628 & 0.036 & \\
\hline \multirow{2}{*}{ Pair 4} & \multirow{2}{*}{$\begin{array}{l}\text { I tell my child what to do with his or her } \\
\text { money. (MC4) }\end{array}$} & MCE4 & 1.98 & 300 & 0.936 & 0.054 & 1.103 \\
\hline & & MCP4 & 0.96 & 300 & 0.919 & 0.053 & \\
\hline \multirow{2}{*}{ Pair 5} & \multirow{2}{*}{$\begin{array}{l}\text { I talk to my child about things we see or } \\
\text { hear advertised. (MC5) }\end{array}$} & MCE5 & 1.91 & 300 & 1.074 & 0.062 & 1.249 \\
\hline & & MCP5 & 0.79 & 300 & 0.667 & 0.039 & \\
\hline \multirow{2}{*}{ Pair 6} & \multirow{2}{*}{$\begin{array}{l}\text { I tell my child why I bought some things } \\
\text { for myself. (MC6) }\end{array}$} & MCE6 & 2.34 & 300 & 1.175 & 0.068 & 1.459 \\
\hline & & MCP6 & 0.78 & 300 & 0.946 & 0.055 & \\
\hline \multirow{2}{*}{ Pair 7} & \multirow{2}{*}{$\begin{array}{l}\text { I talk to my child about saving and } \\
\text { investing money. (MC7) }\end{array}$} & MCE7 & 1.71 & 300 & 0.999 & 0.058 & 1.172 \\
\hline & & MCP7 & 0.71 & 300 & 0.663 & 0.038 & \\
\hline \multirow{2}{*}{ Pair 8} & \multirow{2}{*}{$\begin{array}{l}\text { I talk to my child about things I should } \\
\text { save for. (MC8) }\end{array}$} & MCE8 & 2.12 & 300 & 0.906 & 0.052 & 1.883 \\
\hline & & MCP8 & 0.71 & 300 & 0.548 & 0.032 & \\
\hline \multirow{2}{*}{ Pair 9} & \multirow{2}{*}{$\begin{array}{l}\text { I communicate with my child about } \\
\text { money management. (MC9) }\end{array}$} & MCE9 & 1.7 & 300 & 0.774 & 0.045 & 1.307 \\
\hline & & MCP9 & 0.7 & 300 & 0.756 & 0.044 & \\
\hline \multirow{2}{*}{ Pair 10} & \multirow{2}{*}{$\begin{array}{l}\text { I discuss the importance of saving with } \\
\text { my child. (MC10) }\end{array}$} & MCEIO & 2.14 & 300 & 0.907 & 0.052 & 1.804 \\
\hline & & MCP10 & 0.64 & 300 & 0.748 & 0.043 & \\
\hline \multirow{2}{*}{ Pair 11} & \multirow{2}{*}{$\begin{array}{l}\text { I discuss the importance of a budget } \\
\text { with my child. (MC11) }\end{array}$} & MCEII & 2.15 & 300 & 0.862 & 0.05 & 1.963 \\
\hline & & MCP11 & 0.7 & 300 & 0.586 & 0.034 & \\
\hline \multirow{2}{*}{ Pair 12} & \multirow{2}{*}{$\begin{array}{l}\text { I discuss household finances with my } \\
\text { child. (MC12) }\end{array}$} & MCE12 & 2.42 & 300 & 0.765 & 0.044 & 1.48 \\
\hline & & MCP12 & 1.37 & 300 & 0.653 & 0.038 & \\
\hline \multirow{2}{*}{ Pair 13} & I help my child open and maintain an & MCE13 & 2.02 & 300 & 0.763 & 0.044 & 1.656 \\
\hline & account at a financial institution. (MC13) & MCP13 & 0.72 & 300 & 0.806 & 0.047 & \\
\hline & I allow my child to make decisions about & MCEl4 & 2.57 & 300 & 1.014 & 0.059 & 1.383 \\
\hline Pair 14 & household spending. (MC14) & MCP14 & 0.99 & 300 & 0.832 & 0.048 & \\
\hline & I help my child develop financial goals. & MCE15 & 2.57 & 300 & 0.984 & 0.057 & 2.467 \\
\hline Pair 15 & $(\mathrm{MC15})$ & MCP15 & 0.58 & 300 & 0.581 & 0.034 & \\
\hline & I allow my child to manage their own & MCEl6 & 2.91 & 300 & 0.813 & 0.047 & 1.789 \\
\hline Pair 16 & money. (MC16) & MCP16 & 0.8 & 300 & 0.7 & 0.04 & \\
\hline & I discuss the trade-offs \& consequences & MCEl7 & 1.88 & 300 & 1.02 & 0.059 & 1.295 \\
\hline Pair 17 & $\begin{array}{l}\text { of my child's money management } \\
\text { decisions. (MC17) }\end{array}$ & MCP17 & 0.77 & 300 & 0.669 & 0.039 & \\
\hline & I tell my child why I save and invest. & MCEl8 & 2.35 & 300 & 0.818 & 0.047 & 1.449 \\
\hline Pair 18 & (MC18) & MCP18 & 1.23 & 300 & 0.72 & 0.042 & \\
\hline & I tell my child what he or she should do & MCE19 & 2.2 & 300 & 1.029 & 0.059 & 1.408 \\
\hline Pair 19 & $\begin{array}{l}\text { with his or her savings and investments. } \\
\text { (MC19) }\end{array}$ & MCP19 & 0.94 & 300 & 0.736 & 0.043 & \\
\hline & O & MCE & 2.17 & 300 & 0.215 & 0.012 & 6.625 \\
\hline & Overall Money Communication (MC) & MCP & 0.88 & 300 & 0.172 & 0.009 & \\
\hline
\end{tabular}


The results of paired t-test also reports that the overall money communication between parentadolescent on collectively 19 items of this matched paired scale is derived from taking the average of disparities in the mean value of the 19 pairs in pre-survey and post-survey measures suggested that the disparity between the mean score of parent-adolescent money communication is reduced from $2.17(S D=0.215)$ to $0.88(S D=0.172)(\dagger(299)=101.26, p<0.05)$. This finding concludes that financial education given to the parent has positively enhanced money communication among parentadolescent by reducing the disparity of the responses collected from the parents and adolescents on the matched pairs during pre-survey and post-survey.

Table 3: Paired Samples Test (Paired Differences)

\begin{tabular}{|c|c|c|c|c|c|c|c|c|c|}
\hline \multirow[b]{2}{*}{ Pairs } & \multirow[b]{2}{*}{ Codes } & \multirow[b]{2}{*}{ Mean } & \multirow{2}{*}{$\begin{array}{c}\text { Std. } \\
\text { Deviation }\end{array}$} & \multirow{2}{*}{$\begin{array}{c}\text { Std. Error } \\
\text { Mean }\end{array}$} & \multicolumn{2}{|c|}{$\begin{array}{l}95 \% \text { Confidence } \\
\text { interval of the } \\
\text { Difference }\end{array}$} & \multirow[b]{2}{*}{ t-value } & \multirow[b]{2}{*}{ df } & \multirow{2}{*}{$\begin{array}{c}\text { Sig. } \\
\text { (2-tailed) }\end{array}$} \\
\hline & & & & & Lower & Upper & & & \\
\hline Pair 1 & $\mathrm{MCl}$ & 1.05 & 0.944 & 0.054 & 0.943 & 1.157 & 19.273 & 299 & 0.00 \\
\hline Pair 2 & MC2 & 1.473 & 0.983 & 0.057 & 1.362 & 1.585 & 25.966 & 299 & 0.00 \\
\hline Pair 3 & MC3 & 0.983 & 0.152 & 0.009 & 0.966 & 1.001 & 111.982 & 299 & 0.00 \\
\hline Pair 4 & MC4 & 1.023 & 1.26 & 0.073 & 0.88 & 1.167 & 14.065 & 299 & 0.00 \\
\hline Pair 5 & MC5 & 1.117 & 1.114 & 0.064 & 0.99 & 1.243 & 17.365 & 299 & 0.00 \\
\hline Pair 6 & MC6 & 1.557 & 1.607 & 0.093 & 1.374 & 1.739 & 16.779 & 299 & 0.00 \\
\hline Pair 7 & MC7 & 0.993 & 0.801 & 0.046 & 0.902 & 1.084 & 21.471 & 299 & 0.00 \\
\hline Pair 8 & MC8 & 1.41 & 0.969 & 0.056 & 1.3 & 1.52 & 25.211 & 299 & 0.00 \\
\hline Pair 9 & MC9 & 1 & 0.164 & 0.009 & 0.981 & 1.019 & 105.889 & 299 & 0.00 \\
\hline Pair 10 & MC10 & 1.5 & 1.22 & 0.07 & 1.361 & 1.639 & 21.296 & 299 & 0.00 \\
\hline Pair 11 & MC11 & 1.447 & 1.002 & 0.058 & 1.333 & 1.561 & 25.009 & 299 & 0.00 \\
\hline Pair 12 & MCl2 & 1.053 & 0.301 & 0.017 & 1.019 & 1.088 & 60.549 & 299 & 0.00 \\
\hline Pair 13 & MC13 & 1.3 & 0.909 & 0.052 & 1.197 & 1.403 & 24.774 & 299 & 0.00 \\
\hline Pair 14 & MCl4 & 1.283 & 0.945 & 0.055 & 1.176 & 1.391 & 23.526 & 299 & 0.00 \\
\hline Pair 15 & MC15 & 1.993 & 1.159 & 0.067 & 1.862 & 2.125 & 29.776 & 299 & 0.00 \\
\hline Pair 16 & MCl6 & 2.117 & 1.123 & 0.065 & 1.989 & 2.244 & 32.653 & 299 & 0.00 \\
\hline Pair 17 & MC17 & 1.117 & 0.945 & 0.055 & 1.009 & 1.224 & 20.471 & 299 & 0.00 \\
\hline Pair 18 & MC18 & 1.117 & 0.413 & 0.024 & 1.07 & 1.164 & 46.869 & 299 & 0.00 \\
\hline \multirow[t]{2}{*}{ Pair 19} & MC19 & 1.26 & 0.907 & 0.052 & 1.157 & 1.363 & 24.074 & 299 & 0.00 \\
\hline & MCO & 1.297 & 0.222 & 0.012 & 1.271 & 1.322 & 101.261 & 299 & 0.00 \\
\hline
\end{tabular}

In order to check the extent of change, i.e. effect of financial education workshop series on each item of money communication scale, Cohen's $d$ effect sizes were calculated, for each dependent measure by dividing the value of mean differences of pre-survey to post-survey between groups by their pooled standard deviation. For calculating effect size following formula was used.

$$
d=\frac{M 1-M 2}{\sqrt{(S D 1+S D 2) / 2}}
$$

Where $M 1$ represents the mean score of pre-survey and $M 2$ represents mean post-survey score of measure that is expected to be positively related to the independent variable. SD1 and SD2 show the standard deviation of disparity of responses collected from parent and adolescent in pre-survey and post-survey, respectively. A positive effect size of Cohen's dindicates a financial education workshop series enhances the parent-adolescent money communication by reducing the disparity of money communication perception among parents and adolescents. To know the effect size of each item of parent-adolescent money communication, Cohen's dwas calculated for each separate variable and presented in Table 2. From the last column of Table 2, it can be seen that for all 19 pairs of parent-adolescent communication, the positive value of Cohen's dindicates that 
financial education workshop series has a positive but diverse effect on various items of parentadolescent money communication.

Similarly, to check hypothesis 2 , the linear regression analysis was performed. For this difference in the money communication gap score found from pre-survey and post-survey was taken as an independent variable and financial autonomy score reported in pre-survey, and post-survey was considered as a dependent variable. Before performing linear regression, the correlation coefficient between these two variables was found and was -0.686 , reported a strong negative correlation between the independent variable (money communication score) and dependent variable (financial autonomy) as the value is close to -1. In other words, if the gap frequency in money communication among parent-child is decreased, this led to the enhancement in the financial autonomy of the adolescents.

To check the significant influence of parent-child money communication gap and financial autonomy of the adolescents, the linear regression tests were used as a bi-variate statistical tool. It is used to model the dependence of a variable (single variable) on another explanatory variable (single variable). The functional affiliation then correctly specified as an equation, with associated statistical values that define how well this equation fits the data. The objective of the researcher is to ascertain the causal effect of one variable upon another. The researcher has also assessed the "statistical significance" of the estimated relationship.

The result of regression analysis is presented in Table 4. The correlations co-efficient of financial socialization variables and financial autonomy was -0.682 , reflecting a strong positive correlation between these variables as the value is close to -1. R2indicates the proportion of variance that can be explained in the dependent variable by the independent variable. This measures the strength of the relationship. This displays that $46.5 \%$ of the variation in financial autonomy is explained by the parent-child money communication gap.

\section{Table 4: Model Summary}

\begin{tabular}{l|c|c|c|r|r}
\hline Model & $\mathbf{R}$ & $\mathbf{R}$ Square & Adjusted R Square & Std. Error of the Estimate & Durbin-Watson \\
\hline $\mathbf{1}$ & $-0.682^{a}$ & 0.465 & 0.465 & 0.5807042 & 1.200 \\
\hline
\end{tabular}

a. Predictors: (Constant), MonCom

b. Dependent Variable: FinAuto

F-statistic shown in Table 5 represents the significance of the test of the relationship between independent variables and dependent variable. The $p$-value is below $0.05(p<0.01)$, therefore it is concluded that predicting financial autonomy based on parent-child money communication gap is statistically significant. This means that parent-child money communication gap does have a significant influence on the financial autonomy of the adolescents.

Table 5: ANOVA

\begin{tabular}{l|l|c|c|r|c|c}
\hline Model & & Sum of Square & dfa. & $\begin{array}{r}\text { Mean } \\
\text { Square }\end{array}$ & F & Sig \\
\hline 1 & Regression & 175.575 & 1 & 175.575 & 520.657 & .000 \\
& Residual & 201.656 & 598 & 0.337 & & \\
\hline & Total & $\mathbf{3 7 7 . 2 3 1}$ & $\mathbf{5 9 9}$ & & & \\
\hline
\end{tabular}

a. Predictors (Constant), MonCom

b. Dependent Variable: FinAuto

Table 6 supports to predict the prediction about financial autonomy by a parent-child money communication gap. Accordingly, the following equation is formed:

$Y($ Financial Autonomy) $=4.721-0.799$ (Money communication gap score) 
Table 6: Coefficients

\begin{tabular}{l|c|cc|c|c|c}
\hline \multirow{2}{*}{ Model } & & \multicolumn{2}{|c|}{ Unstandardized Coefficients } & Standardized Coefficients & t & Sig \\
& & B & Std. Error & Beta & & \\
\hline \multirow{2}{*}{1} & (Constant) & 4.721 & 0.058 & & 80.807 & 0 \\
& MonCom & -0.799 & 0.035 & -0.682 & -22.82 & 0 \\
\hline
\end{tabular}

The unstandardized coefficient shown in Table 6 is the value for the intercept (a) in the regression equation, while, the standardized regression coefficient Beta ( $\beta$ ), allows the researcher to compare the relative strength of independent variable's relationship with the dependent variable. In other words, it provides us with information about how much change can be expected in the dependent variable with a one-unit change in each independent variable. Moving through the equation, the value of unstandardized coefficient indicates that on an average one unit increase in parent-child money communication gap will lead to a decrease in financial autonomy by 0.799 unit, keeping other factors constant. The negative t-value for parent-child money communication gap differences suggests the negative effect on the associated financial autonomy of the adolescents. The results of the $\beta$ value show the strength of the association between the independent variable and dependent variable. The negative value of $\beta(-0.682)$ reports the strong negative association between parentchild money communication gap and financial autonomy of the adolescents.

\section{Discussion}

The results of this study have valuable implications for regulatory authorities and providers for financial education, particularly, for the countries where there is no baseline data is available such as India. This study discusses one of the indirect outcomes of financial education workshops implemented for female parents, wherein responses collected from adolescents provide confirmation or crosschecking of the parents' responses about money communication perception. The overall findings of this study provide evidence that the disparity among parent-adolescent money communication (perceptions) is largely reduced by financial education and it is concluded that financial education enhances parent-adolescent money communication, suggesting that workshop series was effective in reaching the participants in their parent-adolescent money communication regarding the management of personal finances at home.

The overall results of paired t-test support the success of financial education workshop series, although, this effect is varied on each item of parent-adolescent money communication which can be identified by Cohen's $d$ as shown in the last column of Table 2.

For interpreting the effect of treatment, Cohen suggested $d=0.2$ considered as a 'small' effect size, $\mathrm{d}=0.5$ represents a 'medium' effect size and 0.8 a 'large' effect size. This means that if two groups' mean values do not differ by 0.2 standard deviations or more, the difference is trivial, even if it is statistically significant. The critical analysis of values of Cohen's $d$ calculated for every 19 items of parent-adolescent communication also suggests that for all the matched pairs of parent-adolescent money communication items, Cohen's $d$ is higher than 0.5 and positive in nature, signifying that financial education workshop series has a larger effect on all the variables of parent-adolescent money communication with a positive change. From the values of Cohen's $d$ as presented in Table 2 show that among all the items of parent-adolescent money communication. The largest positive change is found on pair 15 (MC15), i.e. "I help my child to develop financial goals" (Cohen's $d=2.467$ ) followed by pair 11 (MC11), i.e. "I discuss the importance of a budget with my child" (Cohen's $d=$ 1.963) compared to other items of communication. 
Similarly, the Cohen's $d$ effect size for the rest of pairs of parent-adolescent money communication in descending order was found to be for pair 8 (MC8), i.e. "I talk to my child about things I should save for" (Cohen's $d=1.883$ ), pair 2 (MC2), i.e. "I go for shopping with my child" (Cohen's $d=1.815$ ), pair 10 (MC10), i.e. "I discuss the importance of saving with my child." (Cohen's $d=1.804$ ), pair 16 (MC16), i.e. "I allow my child to manage their own money" (Cohen's $d=1.789$ ) and henceforth. While Cohen's $d$ effect size on the rest of pairs of parent-adolescent money communication in ascending order from the lowest was found to be for pair 4 (MC4), i.e. "I tell my child what to do with his or her money" (Cohen's $d=1.103$ ), pair 7 (MC7), i.e. "I talk to my child about saving and investing money" (Cohen's $d=1.172$ ), pair 5 (MC5), i.e. "I talk to my child about things we see or hear advertised" (Cohen's $d=$ 1.249), pair 1 (MC1), i.e. "I talk to my child about buying things" (Cohen's $d=1.7294$ ).

The close observation of the value of Cohen's $d$ effect size for entire parent-adolescent money communication scale is found to be 6.625. This large value is of Cohen's $d$ is higher than 0.5 and positive in nature, signifying that financial education workshop series has a larger effect on collectively all the variables of parent-adolescent money communication with a positive change. In other words, after providing financial education to female parents through financial education workshop series, the money communication among parent-adolescent is drastically enhanced by reducing the discrepancies of perception of parents and adolescent money communication with each other wherein the follow-up data was collected after six months of the completion of the financial education workshops.

The results of linear regression analysis performed to check the effect of parent-child money communication gap on the financial autonomy of the adolescents suggest that on an average one unit of decrease/increase in parent-child money communication gap will lead to increase/decrease in financial autonomy by 0.799 units considering other factors are constant. The results also report that $46.5 \%$ of the variation in financial autonomy is explained by the parent-child money communication gap.

\section{Conclusion}

The study was conducted in the state of Gujarat, India. Knowing that financial education empowers the participant parents to manage their household money, this research study was initiated with the assumption that financial education may improve the parent-adolescent money communication which would improve the financial autonomy of the adolescents. Starting with this assumption, it was explored whether this improvement in parent-adolescents money communication has any corelation with the financial autonomy of the adolescents. In other words, whether improved parentadolescent money communication also leads to improvement in the financial autonomy of the adolescents? Accordingly, the objective of the research study was to assess whether financial education enhances the parent-adolescent money communication, which in turn leads to improvement in the financial autonomy for the adolescents. To fulfil this research objective, a financial education workshop series was conducted for female parents, as a parent's gender was considered as a controlled variable.

The responses were collected from 300 female parents on parent-adolescent money communication scale consisting of nineteen items before conducting the first financial education workshop and after six months of the completion of the last financial education workshop. Assuming that parents always claim that they usually discuss money importance and its management with children, but their children don't 'hear' them, the matched pair of each money communication item of nineteen variables were framed in the structured questionnaire for adolescents to rate and their children who were in adolescence stage of life were requested to rate each matching item pair of the parent scale. However, parents were not told that their children were also asked to rate the matching pair of each item of parent money communication scale and vice versa. Accordingly, 
these adolescents rated the matching version of parent-adolescent money communication scale twice, once before conducting the first financial education workshop and then six months after completion of the last workshop for their female parent.

The analysis of primary data reveals that enhanced parent-adolescent money communication because of financial education does enhance the financial autonomy of the adolescents not only on the overall scale but also for each paired item under study. The value of Cohen's $d$ also confirms that financial education has a larger positive effect on such type of communication. Thus, this study provides a noticeable conclusion that financial education given to the parent positively enhances money communication among parent-adolescent by reducing the disparity between the responses collected from the parents and adolescents on the matched pairs during pre-survey and post-survey in the context of India and that this reduced disparity between the responses also indicates greater financial autonomy for the adolescents.

Overall, the findings from this study have several implications for financial educators and policymakers. Firstly, enhanced parent-adolescent money communication as a result of financial education workshops appear to strengthen the perception that imparting financial education to the female parent does have a positive impact on the way the adolescent children behave in terms of money matters. Considering that such desired financial autonomy cannot be strengthened in the long run only by one workshop, there must be a series of workshops for the participants. Secondly, post-survey responses revealed that as a result of financial education workshops, the adolescent children might have developed a strong intention to improve their money communication with their parent during the workshop series which has changed their financial habits positively, which has been confirmed by the reduced disparities found from parents' and adolescents' responses. This important outcome provides a likely assumption that developing financial autonomy in adolescents may have been constrained by factors such as "parents' inability or unwillingness to discuss financial matters" and the same is improved by empowering the parents on the subject of personal finance. Thirdly, financial educators and policymakers need to be aware that parents play a crucial role in the socialization process of their children and parents. Parents' instructions and communication with their children not only impacts the children's financial choices but also makes them feel more competent about managing their finances. Hence, along with designing financial education program material and workshops only for children, college students or adults, there is room to design and implement "family-based financial education workshops", which may provide them with an opportunity to learn about household money management to the entire family instead of one family member, this may open the lines of "money communication" between parents and children and lead to greater financial autonomy for the future generations which will bode well for the future of the country on a large scale.

\section{Limitations and Suggestions for Further Research}

This study has several limitations. Firstly, the feedback of the program organizer and educator was not collected. Secondly, the study covered the households from only one district of the state of Gujarat. This limits the generalizability of the findings. Thirdly, the gender of the parent was controlled while the gender of the adolescent (child) was not controlled. This may lead to differences in the responses towards perceptions of female adolescents and male adolescents towards their parent's money communication. Lastly, there is an absence of a control group in this study.

This study provides enough scope for researchers to carry out rigorous experimental research design by employing a control group and much larger sample size from various states. This study can also be extended by controlling the gender of the children so that chances of difference in the responses due to gender bias in parent-child money communication can be overcome. It is also suggested that future studies should employ longer-term follow-up surveys of one or more years to explain the 
sustainable effect of financial education on various financial attitudes, behaviours, and other outcomes.

Figure 1: Normal P-Plot of Regression Standardised Residual

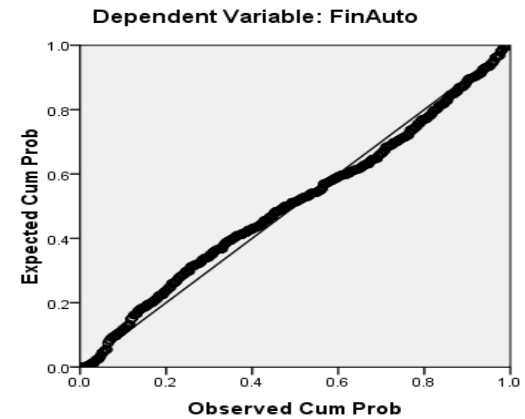

\section{References}

Allen, M. W., 2008. Consumer finance and parent-child communication. In: Xiao, J. J. (Eds.), Handbook of Consumer Finance Research.New York, pp. 351-361.

Atwood, J. D., 2012. Couples and money: The last taboo. The American Journal of Family Therapy 40(1), 119.

Bajtelsmit, V. L. and Bernasek, A. 1996. Why do women invest differently than men? Journal of Financial Counseling and Investing7, pp. 1-10.

Bandura, A (1986). Social Foundations of Thoughts and Actions: A Social Cognitive Theory. Englewood Cliffs: Prentice Hall.

Baltes, M. M., and Silverberg, S. B. 1994. The dynamics between dependency and autonomy: Illustrations across the life span. In: Featherman, D. L., Lerner, R. M., Perlmutter, M. (Eds.), Life-span Development and Behavior, 12, Hillsdale, NJ: Erlbaum, pp. 41-90.

Chen, H. and Volpe, R.P. 1998. An analysis of personal financial literacy among college students. Financial Services Review 7, pp. 107-128.

Collins, W. A., Gleason, T., and Sesma, Jr., A. 1997. Internalization, autonomy, and relationships: Development during adolescence. In: Grusec, J. E., Kuczynski, L. (Eds.), Parenting and Children's Internalization of Values. Wiley.,New York, pp. 78-102.

Connell, J. P., 1990. Context, self, and action: A motivational analysis of self-system processes across the life span. In: Cicchetti, D., Beeghly, M. (Eds.), The Self in Transition: Infancy to Childhood, Chicago, IL: University of Chicago Press, pp. 61-97.

Danes, S. M., 1994. Parental perceptions of children's financial socialization. Journal of FinancialCounseling and Planning, 5, pp. 127-149.

Deci, E.L., and Ryan, R.M., 2000. The "what" and "why" of goal pursuits: Human needs and the selfdetermination of behavior. Psychological Inquiry 11, pp. 227-268. 
DeVaney, S. A., Gorham, E. E., Bechman, J. C. and Haldeman, V. A., 1996. Cash flow management and credit use: effect of a financial information program. Financial Counseling and Planning 7, pp. 71-79.

Financial Literacy and Education Commission 2006. Taking Ownership of the Future: The National Strategy for Financial Literacy. US Department of Treasury, http://www.treasury.gov/offices/domesticfinance/financial-institution/fin-education/support-docs/Strategyeng.pdf, accessed 12 June 2019.

Fox, J., Bartholomae, S., and Gutter, M.S., 2000. What do we know about socialization? Consumer Interest Annual 46.

Furnham, A., and Argyle, M., 1998. The Psychology of Money. Florence, KY, US: Taylor \& Frances: Routledge.

Garman, E.T., Kim, J., Kratzer, D.Y., Brunson, B.H. and Joo, S., 1999. Workplace financial education improves personal financial wellness. Financial Counseling and Planning 10(1), pp. 79-99.

Government of India 2011. Census of India. Ministry of Home Affairs, Government of India, New Delhi.

Hogarth, J. M., Beverly, S.G. and Hilgert, M.A., 2003. Patterns of financial behavior: implications for community educators and policy makers. Discussion draft presented at Federal Reserve System Community Affairs Research Conference, February.

Kalil, A., Ziol-Guest, K. M., and Coley, R. L., 2005. Patterns of father involvement in teenage-mother families: Predictors and links to mothers' psychological adjustment. Family Relations 54, pp. 197-211.

Jariwala, H. V., and Sharma, M., 2013. Assessment of behavioral outcomes of financial education workshops on financial behavior of the participants: An experimental Study. Journal of Financial Services Marketing 18 (3), pp. 241-256.

Jariwala, H., and Dziegielewski, S., 2017. Pathway to financial success: Autonomy through financial education in India. Journal of Social Service Research 43, pp. 381-394.

Jorgensen, B., and Savla, J., 2010. Financial literacy of young adults: The importance of parental socialization. Family Relations 59(4), pp. 465-478.

Joo S. 2008. Personal Financial Wellness. In: Xiao J.J. (Eds.), Handbook of Consumer Finance Research. Springer, New York, pp. 21-33.

Koonce, J. C., Mimura, Y., Mauldin, T. A., Rupured, A. M., and Jordan, J., 2008. Financial information: Is it related to savings and investing knowledge and financial behavior of teenagers? Journal of FinancialCounseling and Planning 19, pp. 19-28.

Laible, D., and Thompson, R. A., 2007. Early socialization: A relationship perspective. In: Grusec, J. E., Hastings, P. D., (Eds.), Handbook of Socialization:Theory and Research. Guilford Press, New York, pp. 181 207.

Lusardi, A., 2004. Savings and the effectiveness of financial education. In: Mitchell, O. S. and Stephen U. (Eds.), Pension Design and Structure: New Lessons from Behavioral Finance.Oxford University Press, Oxford, pp. 157-184.

Lusardi, A., 2011. A Framework for evaluating financial education programmes. In: OECD Improving financial education efficiency: OECD-Bank of Italy Symposium on financial literacy, OECD Publishing: 4362.

Lusardi, A., and Mitchell, O.S., 2009. How ordinary consumers make complex economic decisions: Financial literacy and retirement readiness. Massachusetts Ave., Cambridge: National Bureau of Economic Research. NBER Working Paper no. 15350. 
Lyons, A. C., Chang, Y., and Scherpf, E. M., 2006. Translating financial education into behavior change for low-income populations. Journal of Financial Counseling and Planning 17 (2), pp. 27-45.

Mandell, L., 2001. Improving financial literacy: What schools and parents can and cannot do. Washington, DC: Jump\$tart Coalitions for Personal Financial Literacy.

Mandell, L., 2009. The impact of financial education in high school and college on financial literacy and subsequent financial decision making. Paper Presented at the American Economic Association Meetings; 4 January, San Francisco, CA.

Micarello, H., Melo, M. P., and Marcelo, B. B., 2012. Application of the CAEd Autonomy Scale to Assess the Impact of Financial Education, CAEd Academic Publications Online.

Moore, R.L., and Stephens, L.F., 1975. Some communication and demographic determinants of adolescent consumer learning. Journal of Consumer Research 2, pp. 80-92.

Moschis, G.P., and Churchill, G.A., 1978. Consumer socialization: A theoretical and empirical analysis. Journal of Marketing Research, 15, pp. 599-609.

Moschis, G. P., 1985. The role of family communication in consumer socialization of children and adolescents. Journal of Consumer Research 11 (4), pp. 898-913.

Moschis, G. P., 1978. Consumer socialization: A lifecycle perspective. Massachusetts: Lexington Books.

Noom, M. J., Dekovic, M., and Meeus, W., 2001. Conceptual analysis and measurement of adolescent autonomy. Journal of Youth and Adolescence 30 (5), pp. 577-595.

O'Connell, A., 2009. Evaluating the effectiveness of financial education programmes. OECD Journal: General Papers 2008/3.

Otto, A., Schots, P. A., Westerman, J. A., and Webley, P., 2006. Children's use of saving strategies: An experimental approach. Journal of Economic Psychology,27, pp. 57-72.

Petronio, S., 2002. Boundaries of privacy: Dialectics of disclosure. New York: State University of New York Press.

Prochaska, J., 1979. Systems of Psychotherapy: A Trans-theoretical Analysis. Homewood, III: Dorsey Press.

Ryan, R. M., and Lynch, J., 1989. Emotional autonomy versus detachment: Revising the vicissitudes of adolescence and young adulthood. Child Development, 60, pp. 340-356.

Sharma, M., and Jariwala, H. 2011. Financial literacy: A call for an attention. International Journal of Academic Conference Proceedings 1 (1), Library of Congress, Washington.

Taylor, P., 2003. Gender gap creates niche in financial services. Financial News, 8 March, p. 24.

Violato, M., Petrou, S., Gray, R., andRedshaw, M., 2011 . Family income and child cognitive and behavioral development in the United Kingdom: Does money matter? Health Economics 20(10), pp. $1201-1225$.

Webley, P., and Nyhus, E. K., 2006. Parents' influence on children's future orientation and saving. Journal ofEconomic Psychology 27(1), pp. 140-164. 


\section{Appendix 1}

\begin{tabular}{|c|c|c|}
\hline \multicolumn{3}{|c|}{ Parent-adolescent money communication scale for parent and adolescent matched pairs } \\
\hline Pairs & Money Communication (Scale for parents) & Matching question for Adolescents \\
\hline 1 & I talk to my child about buying things. & This parent and I talk about buying things. \\
\hline 2 & I go for shopping with my child. & I go for shopping with this parent. \\
\hline 3 & $\begin{array}{l}\text { I tell my child what things he or she should or should } \\
\text { not buy. }\end{array}$ & This parent tells me what things I should buy or not buy. \\
\hline 4 & I tell my child what to do with his or her money. & This parent tells me what they do with their money. \\
\hline 5 & $\begin{array}{l}\text { I talk to my child about things we see or hear } \\
\text { advertised. }\end{array}$ & This parent talks about things we see or hear advertised. \\
\hline 6 & I tell my child why I bought some things for myself. & $\begin{array}{l}\text { This parent tells me why they bought some things for } \\
\text { themselves. }\end{array}$ \\
\hline 7 & I talk to my child about saving and investing money. & $\begin{array}{l}\text { This parent and I talk about saving and investing } \\
\text { money. }\end{array}$ \\
\hline 8 & I talk to my child about things I should save for. & This parent and I talk about things I should save for. \\
\hline 9 & $\begin{array}{l}\text { I communicate with my child about money } \\
\text { management. }\end{array}$ & $\begin{array}{l}\text { This parent talks to me about money } \\
\text { management. }\end{array}$ \\
\hline 10 & I discuss the importance of saving with my child. & This parent discusses the importance of saving with me. \\
\hline 11 & I discuss the importance of a budget with my child. & $\begin{array}{l}\text { This parent discusses the importance of a } \\
\text { budget with me. }\end{array}$ \\
\hline 12 & I discuss the household finances with my child. & $\begin{array}{l}\text { This parent talks to me about household } \\
\text { finances. }\end{array}$ \\
\hline 13 & $\begin{array}{l}\text { I help my child open and maintain an account at a } \\
\text { financial institution. }\end{array}$ & $\begin{array}{l}\text { This parent has helped me open and maintain an } \\
\text { account at a financial institution. }\end{array}$ \\
\hline 14 & $\begin{array}{l}\text { I allow my child to make decisions about household } \\
\text { spending. }\end{array}$ & $\begin{array}{l}\text { This parent allows me to participate in } \\
\text { decisions about household spending. }\end{array}$ \\
\hline 15 & I help my child develop financial goals. & This parent helps me develop financial goals. \\
\hline 16 & I allow my child to manage their own money. & $\begin{array}{l}\text { This parent allows me to manage my own } \\
\text { money. }\end{array}$ \\
\hline 17 & $\begin{array}{l}\text { I discuss the trade-offs and consequences of my } \\
\text { child's money management decisions. }\end{array}$ & $\begin{array}{l}\text { This parent discusses trade-offs and } \\
\text { consequences of my money management } \\
\text { decisions. }\end{array}$ \\
\hline 18 & I tell my child why I save and invest. & This parent tells me for what they save and invest. \\
\hline 19 & $\begin{array}{l}\text { I tell my child what he or she should do with his or her } \\
\text { savings and investments. }\end{array}$ & $\begin{array}{l}\text { This parent tells me what they do with their savings and } \\
\text { investments. }\end{array}$ \\
\hline
\end{tabular}

\section{Appendix 2: Financial Autonomy Statements}

\begin{tabular}{|c|c|c|}
\hline Pre-survey code & Post-survey code & FINANCIAL AUTONOMY VARIABLES \\
\hline & & Reflexive Autonomy \\
\hline El & $\mathrm{Pl}$ & I like to think thoroughly before deciding to buy something. \\
\hline E2 & P2 & I like to research prices whenever I buy something. \\
\hline E3 & P3 & I make sure to get information on warranty periods. \\
\hline E4 & P4 & I always try to obtain more information on product quality. \\
\hline \multirow[t]{2}{*}{ E5 } & P5 & $\begin{array}{l}\text { I pay attention to news about the economy as it may affect my } \\
\text { family. }\end{array}$ \\
\hline & & Emotional Autonomy \\
\hline E6 & P6 & $\begin{array}{l}\text { I like to participate in family decision making when we buy something } \\
\text { expensive for home. }\end{array}$ \\
\hline E7 & P7 & I usually have a critical view of the way my friends deal with money. \\
\hline E8 & P8 & I take part in domestic expense planning. \\
\hline E9 & P9 & I try to advise my children on money matters. \\
\hline \multirow[t]{2}{*}{ E10 } & P10 & $\begin{array}{l}\text { I feel prepared to talk to my children and spouse about money } \\
\text { matters. }\end{array}$ \\
\hline & & Functional Autonomy \\
\hline E11 & P11 & I always try to save some money to do things I really like. \\
\hline E12 & P12 & I always like to negotiate prices when I buy. \\
\hline E13 & $\mathrm{P} 13$ & I suggest at home that we keep money aside for emergencies. \\
\hline El4 & $\mathrm{P} 14$ & I keep an eye on promotions and discounts. \\
\hline E15 & P15 & I am willing to make sacrifices now to buy something important. \\
\hline
\end{tabular}

